\title{
Analyzing the Critical Reflection of Equity- and Identity-Focused Professional Learning: A Pilot Study
}

\author{
Teresa Caswell \\ Johns Hopkins University, USA
}

\begin{abstract}
The faculty of an elementary school $(N=82)$ were provided equity- and identity-focused professional learning sessions that included critical reflection. Anonymous race-reflective journal prompts were aligned to a leveled typology of critical reflection to investigate the research question: In what ways do Pre-K-5 staffs' critical reflection approach levels change over time when responding to a racereflective journaling prompt immediately following equity professional development sessions? To analyze submitted journal responses, a pilot response typology was developed as a companion to the existing prompt-typology. While overall increases in level of critical reflection were noted, findings indicated that participants' growth is non-linear; it waxes and wanes depending on the individual, topic, and context. Use se of the response typology in future research and across contexts is needed to determine transferability and dependability.
\end{abstract}

Keywords: critical reflection, pilot study, racereflective journals, transformational learning

\section{Introduction}

Researchers postulate that culturally responsive instruction is a key factor towards ameliorating academic disparities between racialized student subgroups [1]. While student improvements may initially be seen with this approach, staff without higher levels of cultural competence may not experience the transformational learning needed to effectively implement culturally responsive instruction consistently.

A recent pilot study [2] sought to determine if equity- and identity-focused professional development, embedded with critical reflection journaling as an intervention, positively changed participants' cultural competence. The researcher used a developed typology [3] to create prompts designed to support critical reflection leading to transformational change. However, to analyze submitted journals, the researcher needed to create a parallel typology of characteristics indicative of critical reflection responses. This paper aims to share the findings of the qualitative section of the pilot study and the resultant response typology that emerged.

\section{Literature review}

\subsection{Transformational learning and critical reflection}

To encourage improved critical reflection, it is important to consider how adults learn and implement changes to their beliefs. Transformative learning theory describes the process of how one's frame of reference, defined as structures of personal understanding, impacts how individuals acquire new meaningful information [4]. Transformative learning theory further proposes that for new learning to be effective, critical reflection of our assumptions are necessary to understand alternative points of view and thus necessary to integrate new information into one's established frame of reference [4]. This critical selfreflection of assumptions as described by [5] Mezirow (1998) differs from reflection, or the broad process of exploring one's actions and responses to actions [6]. In contrast, the focused process of critical reflection calls upon the examination of one's existing beliefs to, ultimately, extend or transform them [3], [5], [6]. Therefore, critical reflection activities added to professional learning asks participants to analyze their assumptions of beliefs instead of, or in conjunction with, their experiences. This process encourages transformational learning [4], [5], and may lead to increased social justice efforts [3], [7].

\subsection{Race-reflective journaling}

Race-reflective journaling is described as a potential method to capture teachers' critical reflections of racial influences inherent in their work and in their personal lives [8]. These written reflections should be supported through provided prompts and developed typologies [8], [9]. Moreover, critical reflection of cultural consciousness factors should be couched in a realistic situation and supported through realistic experiences [10]. This is important advice when adding critical reflection to an equity and identity-focused professional learning intervention. The resulting race-reflective journal prompts [8] should be designed to elicit authentic reflections teachers have or are experiencing [10] as they move through the transformative learning process [4]. 


\subsection{Critical reflection as an intervention}

If considered as an intervention, critical reflection is operationalized as ones' analysis of their beliefs and biases, and the sociocultural and political conditions that developed them, leading to a reform of actions in support of educational and social justice [3]. Designing critical reflection activities to support an intervention is a flexible process with a variety of strategies, types, and intensities to support educational equity [3], [11], and to improve instruction [8], [12]. Examples include embedded and non-embedded responses to experiences, prompts, and discussions that span a range of depth in terms of equity and/or social justice [3], [7].

The connection of cultural relevancy to the development of critical reflection activities was investigated in three case studies of pre-service teachers enrolled in an elementary teaching program [12]. Each study consisted of an individual interviewed three times (approximately one-hour each) over ten months in addition to analyzing participants' course-required, written reflections (from different professors) as part of their education program. The researchers concluded with a recommendation for teacher preparation programs to ensure provision of cultural experiences and opportunities to critically reflect on them to preservice teachers to develop the skills necessary to support every student [12].

Analysis of multicultural and social justice course assignment activities was the focus of a qualitative study using critical content analysis to determine the depth of critical reflection expected within pre-service teacher assignment descriptions [3]. As the researchers reviewed, coded, discussed, and came to consensus on which assignments required critical reflection compared to those that just required reflection, and expanding on previous approaches to delineating types of critical reflection research, the following typology of approaches to reflection in MSJTE courses developed (see Table 1). The authors note that outside of the conservative approach and its dangers of encouraging racial assimilation, that liberal reflection approaches are important and a valuable bridge towards critical reflections.

\section{Methodology}

This paper focuses on the qualitative section of a larger quasi-experimental, embedded mixed-method design with the research question:

In what ways do Pre-K-5 staffs' critical reflection approach levels change over time when responding to a race-reflective journaling prompt immediately following equity professional development sessions?
Table 1. Excerpt from Gorski and Dalton's typology of reflective approaches to reflection [3]

\begin{tabular}{|l|l|}
\hline Approach (level) & \multicolumn{1}{|c|}{ Definition } \\
\hline $\begin{array}{l}\text { I. Amorphous } \\
\text { "cultural" } \\
\text { reflection } \\
\text { (Conservative) }\end{array}$ & $\begin{array}{l}\text { To reflect broadly on one's } \\
\text { understandings of "other" cultures, } \\
\text { usually in an essentializing way. }\end{array}$ \\
\hline $\begin{array}{l}\text { II. Personal } \\
\text { identity reflection } \\
\text { (Liberal) }\end{array}$ & $\begin{array}{l}\text { To reflect on one's personal identities } \\
\text { without grappling with the implications } \\
\text { of difference or power or how identities } \\
\text { influence one's worldviews or } \\
\text { understandings of justice. }\end{array}$ \\
\hline $\begin{array}{l}\text { III. Cultural } \\
\text { competence } \\
\text { reflection } \\
\text { (Liberal) }\end{array}$ & $\begin{array}{l}\text { To reflect on one's teaching practice } \\
\text { with "diverse learners" in light of one's } \\
\text { identities and life experiences. }\end{array}$ \\
\hline $\begin{array}{l}\text { IV. Equitable and } \\
\text { just school } \\
\text { reflection } \\
\text { (Critical) }\end{array}$ & $\begin{array}{l}\text { To reflect on one's preparedness and } \\
\text { willingness to be an agent of social } \\
\text { justice change in a school context. }\end{array}$ \\
\hline $\begin{array}{l}\text { V. Social } \\
\text { transformation } \\
\text { reflection } \\
\text { (Critical) }\end{array}$ & $\begin{array}{l}\text { To reflect on one's preparedness and } \\
\text { willingness to be an agent of social } \\
\text { justice change in and out of school } \\
\text { contexts and to reflect on the areas of } \\
\text { continued growth one needs to be an } \\
\text { agent of social justice change. }\end{array}$ \\
\hline
\end{tabular}

The purpose of the study was to determine the extent to which increasing a critical reflection prompt resulted in an increase in critical reflection approaches.

\subsection{Context and participants}

The intervention study occurred at a highly diverse and affluent elementary school located in a southwest state in the U.S.; approximately $12 \%$ of students qualify for free or reduced lunch and $76 \%$ identify as students of color. During the 2020-2021 academic year, the school served approximately 803 prekindergarten through fifth grade students with 82 faculty members. Faculty included the researcher as principal, administrators, office staff, classroom teachers, special education and intervention teachers, academic coaches, enhancement teachers, English as a Second Language teachers, a media specialist, and a school counselor; $50 \%$ of staff identified as individuals of color and $92 \%$ were female.

Qualitative data were collected from 28 volunteer participants, or $34 \%$, who consented to anonymously share their race-reflective journals before the start of the intervention study. After the last session, 26, or $32 \%$, sent their journals to the researcher's advisor for analysis.

\subsection{Instrumentation}

Prompts developed with a critical reflection typology were presented to participants as an intervention using race-reflective journaling. Specific question prompts, or a typology of question types, are 
more effective than general reflections around race [8]. Thus, the researcher developed 12 specific prompts aligned with a typology of critical reflection [3].

Using a cognitive interview process, where individuals engage in verbal processing of each question, providing face validity of each questions' intent [13], the researcher finalized six critical reflection prompts (Table 2). Three Johns Hopkins School of Education faculty members were interviewed separately via zoom video conferencing. Each interview was recorded, and the researcher captured additional information, such as the participants' confusion or excitement, about each potential critical reflection prompt.

\subsection{Intervention procedure}

Provided equity- and identity-focused intervention activities occurred over a five month period during six full faculty meetings, each lasting between 75 and 105 minutes within the regular workday. Time for journaling using the developed critical reflection prompts was also included in these job-embedded professional development sessions. Researchers have noted that embedding implicit bias critical reflection into the workday, connected to authentic day to day experiences, increases the overall feeling of relevancy for implicit bias/equity PD participants [10], [14]. Due to the Covid-19 pandemic, all intervention activities occurred online.

\section{Findings}

The purpose of this pilot research was to examine the impact of a pilot intervention, combining equityand identity-focused professional learning sessions with critical reflection using race-reflective journaling, on elementary staff's changes in critical reflection depth and subsequent levels of cultural competency. The following findings focus solely on changes to critical reflection within that study.

Table 2. Final critical reflection prompts by intervention session

\footnotetext{
Session One: Reflect on how your life experiences, beliefs, perceptions, and education have led to your current ideas about working with diverse student populations.

Session Two: What does oppression mean to you? How does implicit bias contribute to that definition? What can you do about it?

Session Three: How do you identify racially or ethnically? Describe what that identification means to you, now, in this environment? Does the description you provided meet your ideal? Why or why not?

Session Four: How do I, as an educator, come to understand the educational experiences of others? How do I ensure all students feel a sense of worth and meet their potential?
}

Session Five: Is it important to discuss microaggressions "in the moment?" Why or why not? Describe a time when you took the opportunity to respond, or a time you wish you had?

Session Six: Am I willing to speak about race to support those who might not be present in the conversation? Are there spaces where I would be less likely to express injustices of race?

\subsection{Development of a companion response typology}

It was noted that each critical reflection prompt was developed using a typology of approach-levels as a guide [3]. This tool was not meant to assess the subsequent reflections of participants responding to the prompt and so the researcher worked to develop a companion typology (Table 3 ). The resultant response approaches were used to guide directed content analyses where existing frameworks, in this case both the prompt and response typologies, guide a priori themes and the resulting evidence will support or discount participant growth within [15]. Thus, the researcher could determine the degree participants of this pilot study developed critical reflection responses to prompts intended to support their transformational learning.

Table 3. Proposed critical reflection response typology

\begin{tabular}{|l|l|}
\hline \multicolumn{1}{|c|}{ Response approach } & \multicolumn{1}{|c|}{ Response definition } \\
\hline $\begin{array}{l}\text { I. Essentializing } \\
\text { Others }\end{array}$ & $\begin{array}{l}\text { Respondents ambiguously focus } \\
\text { on culture in a way that } \\
\text { stereotypes themselves or others } \\
\text { including the use of othering' } \\
\text { language }\end{array}$ \\
\hline $\begin{array}{l}\text { II. Personal identity } \\
\text { experiences } \\
\text { connection to the identities } \\
\text { of others }\end{array}$ & $\begin{array}{l}\text { Individuals looking past } \\
\text { 'culture' to various aspects of } \\
\text { identity' without considering } \\
\text { how those identities can be } \\
\text { connected or their part in a } \\
\text { greater worldview }\end{array}$ \\
\hline $\begin{array}{l}\text { III. Acknowledging other } \\
\text { identities in isolation }\end{array}$ & $\begin{array}{l}\text { Cultural competency and } \\
\text { diversity ideas are expressed yet } \\
\text { do not include reflecting how to } \\
\text { advocate for those that are } \\
\text { marginalized and oppressed }\end{array}$ \\
\hline $\begin{array}{l}\text { IV. Examining how to effect } \\
\text { educational change }\end{array}$ & $\begin{array}{l}\text { Individuals consider their } \\
\text { specific positionality and how to } \\
\text { explicitly effect social justice in } \\
\text { schools }\end{array}$ \\
\hline $\begin{array}{l}\text { Consideration of needed support } \\
\text { and the willingness to be an } \\
\text { and advocacy }\end{array}$ & $\begin{array}{l}\text { agent of social justice in and out } \\
\text { of school; to push oneself to } \\
\text { examine their complicity in } \\
\text { oppression in school and } \\
\text { connect to social justice interests } \\
\text { throughout society }\end{array}$ \\
\hline
\end{tabular}

\subsection{Quantitized response levels}

All journal prompts were designed around two of [3] Gorski and Dalton's (2019) critical reflection approaches: acknowledging others in isolation (level 
3; prompts 1-3) and examining how to effect educational change (level 4; prompts 4-6). The researcher chose these approaches to critical reflection for this intervention pilot study to support faculty's reflection opportunities centered on multicultural competence (level 3), and to foster deep personal reflection of oppression and all forms of injustice (level 4) [3]. By crafting prompts using approaches three and four, participants were presented with activities explicitly aligned to understanding identity and critical reflection. Without this explicit prompting, participants will often adopt a less critical approach [3].

During the coding process, within a priori themes, the researcher compared the approach-level of participants' responses to the developed definitions (see Table 3) to determine if, indeed, participants engaged in critical reflection. The subsequent assigned approach-levels to individual journal responses for each session were quantitized (see Figure 1) to visually determine how participants' critical reflection may have changed after engaging in equity- and identity-focused professional development over time. As shown, as a whole, journal participants did increase their level of critical reflection responses over the course of the intervention.

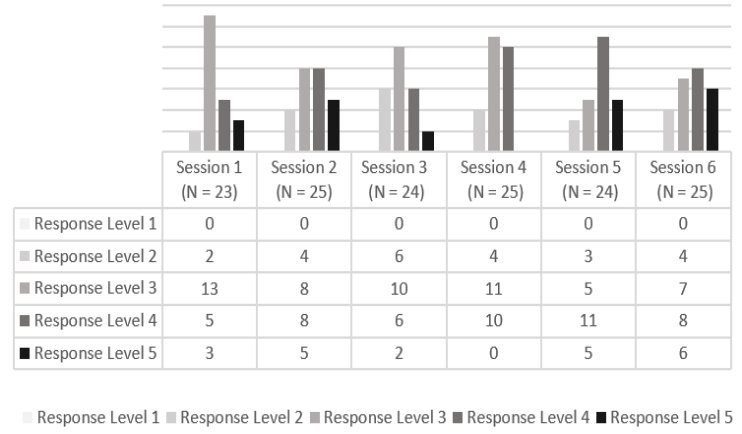

Figure 1. Level of journal response by session prompt

\subsection{Qualitative findings across and within sessions}

The findings by session prompt, developed at prompt approach-levels three and four, elicited a range of responses at approach-levels two through five throughout the intervention sessions [2]. The quantitized data (Figure 1) and qualitative findings by response approach-level seemed to indicate an overall increase in critical reflection as written by participants in their journal entries across the six intervention sessions. While many responses either matched or exceed the approach-level the prompt was written to elicit, others indicated lower levels of reflection for that prompt/content. For example, the session six intervention focused on colorism, or discrimination based on skin tone. Directed content analysis of volunteered journal entries indicated an overall theme of needing support, comfort, and safety. Participants were provided pseudonyms and one, Bonnie expressed her personal needs and what she would need to discuss race with others:

My experience of these types of difficult conversations [about race] is that they require preparation and holding a clear goal in mind, on my part. I have to be invested in maintaining a relationship in order to do this kind of work.

This response was indicative of level two, and while lower than the level four prompt, Bonnie demonstrated an understanding of her needs to move forward.

Ulrich, however, went beyond the session six, level four, prompt with his response:

I hope that I am just as likely to express my beliefs when there is a person of color present. I think it happens less often because people often reserve their prejudice comments and behaviors for when they are with same race people. I am working to eliminate those spaces where it is uncomfortable and continue to express my views in a positive and thoughtful manner without anger.

The level five reflection, as analyzed using the response typology, was indicative of Ulrich wanting to be able to speak up about race in support of others regardless of who is present and how he's working to achieve that advocacy goal. While [3] Gorski and Dalton (2019) stressed that the depth of reflection necessary to ensure transformative learning follows prompts designed to probe issues of power and oppression, these activities do not happen in a vacuum.

The excerpts included in these findings are examples found throughout the 26 volunteer journal participants and demonstrates how participants continued a focus on equity and identity-focused professional learning while experiencing external factors outside of their control; these included a global pandemic and ongoing racial conflict within the 2020 summer and fall months. These findings highlight an understanding that the trajectory of an individual's growth is predicated on a variety of factors and a single prompt-response will not tell one's full story.

Over time, participants increased their overall depth of critical reflection to grapple with the cognitive dissonance sparked by professional learning sessions and captured in their race-reflective journals. As the professional development centered on equityand identity-focused activities, the frames of reference [4] that may be changed center on understanding oneself and thus the identities of others. 


\section{Conclusions}

These qualitative findings centered the change in participants critical reflection approach-levels over time. Directed content analysis [15] was used to analyze participants' journal entries using the researchers' developed response typology as an existing theory and extended [3] Gorski and Dalton's (2019) typology from a prompt-development tool to a prompt-response analysis tool. Authors [15] Hsieh and Shannon (2005) noted that directed content analysis offers options to refine, extend, and enrich existing theory.

In this pilot study, the qualitative analysis of journal participants provided insights that the level of prompt does not ensure corresponding approach-level responses [2]. While the provided journal entries, as a whole, illustrated growth in participants' critical reflection over the course of the intervention, many individual entries waxed and waned from one session to the next. Yet, without critical reflection levels of prompting, participants may not have had the framing necessary to truly consider ideas of equity, identity, oppression, power, and social justice [3] necessary to reconsider established assumptions. The resultant analyses of journal responses indicated an ongoing personal challenge of previous beliefs and thus a potential move towards transformational change [4], [5].

Several limitations were present in this study including those related to positionality, pilot studies, and sample size. As principal of the school context and researcher, I had positional authority over the participants of this study, regardless of how carefully I checked my biases and how often I reiterated to staff their ability to opt-out. However, the positive relationships built with the faculty also indicate that positionality can be an asset to a pilot study with individuals more open to participate than with an unknown researcher. Additionally, field notes and a principal journal were meticulously kept to triangulate qualitative findings and ensure that analyses were couched in reality, versus overly positive remembrances biased to the relationship between the researcher and her faculty.

Pilot studies should be noted as a limitation in that they are determining the feasibility of a confirmatory study [16]. Pilot studies work through the limitations of smaller sample sizes and any revisions needed to improve a study or intervention. Moving forward, a larger study is recommended that includes the combined critical reflection prompt-response typology to determine its generalizability and trustworthiness.

\section{References}

[1] Bottiani, J. H., Larson, K. E., Debnam, K. J., Bischoff, C. M., and Bradshaw, C. P. (2018). Promoting educators' use of culturally responsive practices: A systematic review of in-service interventions. Journal of Teacher Education, 69(4), 367-385.

[2] Caswell, T. A. (2021). Critically reflecting on equityand identity-focused professional learning to increase cultural competency: A pilot study. Unpublished dissertation. Johns Hopkins University.

[3] Gorski, P., and Dalton, K., (2019). Striving for critical reflection in multicultural and social justice teacher education: Introducing a typology of reflection approaches. Journal of Teacher Education.

[4] Mezirow, J. (1997). Transformative learning: Theory to practice. New Directions for Adult and Continuing Education, 1997(74), 5-12.

[5] Mezirow, J. (1998). On critical reflection. Adult Education Quarterly, 48, 185-198.

[6] Fook, J. (2015). Reflective practice and critical reflection. Handbook for practice learning in social work and social care: Knowledge and theory, 3 .

[7] Liu, K., and Ball, A. F. (2019). Critical reflection and generativity: Toward a framework of transformative teacher education for diverse learners. Review of research in Education, 43(1), 68-105.

[8] Milner, H. R. (2003). Teacher reflection and race in cultural contexts: History, meanings, and methods in teaching. Theory into practice, 42(3), 173-180.

[9] Howard, T. C. (2003). Culturally relevant pedagogy: Ingredients for critical teacher reflection. Theory into practice, 42(3), 195-202.

[10] Gay, G., and Kirkland, K. (2003). Developing cultural critical consciousness and self-reflection in preservice teacher education. Theory into practice, 42(3), 181-187.

[11] Liu, K. (2015). Critical reflection as a framework for transformative learning in teacher education. Educational Review, 67(2), 135-157.

[12] Durden, T. R., and Truscott, D. M. (2013). Critical reflectivity and the development of new culturally relevant teachers. Multicultural Perspectives, 15(2), 73-80.

[13] Desimone, L. M., and Le Floch, K. C. (2004). Are we asking the right questions? Using cognitive interviews to improve surveys in education research. Educational Evaluation and Policy Analysis, 26.

[14] Camburn, E. M., and Han, S.W. (2017). Teachers' professional learning experiences and their engagement in reflective practice: A replication study. School Effectiveness and School Improvement, 28, 527-554.

[15] Hsieh, H. F., and Shannon, S. E. (2005). Three approaches to qualitative content analysis. Qualitative health research, 15(9), 1277-1288.

[16] Lee, E. C., Whitehead, A. L., Jacques, R. M., and Julious, S. A. (2014). The statistical interpretation of pilot trials: should significance thresholds be reconsidered? BMC medical research methodology, 14(1), 1-8. 